\title{
Effect of 125-150 Hz Vibrational Frequency Electric Toothbrush on Teeth and Supporting Structures: A Finite Element Method Study
}

\author{
Anadha N Gujar ${ }^{1}$, Prashantha G Shivamurthy ${ }^{2}$, Sharanya Sabrish ${ }^{3}$
}

\begin{abstract}
Aim and objective: The aim of this finite element method (FEM) study was to assess the safety of $125-150 \mathrm{~Hz}$ vibrational frequency electric toothbrush on teeth and associated structures.

Materials and methods: A three-dimensional (3D) geometric model of entire skull having maxilla, mandible, and their dentitions was created using a computed tomography (CT) image of a healthy male patient. Linear static analysis was carried out by applying $15 \mathrm{~g}$ of force on anterior part of maxilla and mandible from labial and lingual sides each to calculate the primary displacement (sagittal, vertical, and transversal) and principal stress levels generated on the maxillary and mandibular dentition, on the maxilla and mandible and on the whole skull.

Results: A force of $15 \mathrm{~g}$ applied to maxillary anterior teeth from labial side caused a mean deflection of $0.003 \mathrm{~mm}$ and stress of $0.004 \mathrm{MPa}$ on the teeth and supporting structures. A force of $15 \mathrm{~g}$ applied to maxillary anterior teeth from palatal side caused a mean deflection of $0.017 \mathrm{~mm}$ and stress of $0.017 \mathrm{MPa}$ on the teeth and supporting structures. A force of $15 \mathrm{~g}$ applied to mandibular anterior teeth from labial side caused a mean deflection of $0.078 \mathrm{~mm}$ and stress of $0.051 \mathrm{MPa}$ on the teeth and supporting structures. A force of $15 \mathrm{~g}$ applied to mandibular anterior teeth from lingual side caused a mean deflection of $0.077 \mathrm{~mm}$ and stress of $0.051 \mathrm{MPa}$ on the teeth and supporting structures.

Conclusion: For the applied loads and boundary conditions, very small or negligible amount of stresses were observed in maxilla, mandible, and their dentitions. The vibrational frequency of $150 \mathrm{~Hz}$ producing $15 \mathrm{~g}$ of force did not produce any harmful effects on maxilla, mandible, and their dentitions. Hence, $125-150 \mathrm{~Hz}$ of vibrational frequency can be considered optimum.

Clinical significance: An electric toothbrush using the vibration of $125-150 \mathrm{~Hz}$ produces negligible stress on teeth and associated structures. Keywords: Electric toothbrush, Finite element analysis, Finite element model, Mechanical vibration, Safe range, Vibrational frequency.

The Journal of Contemporary Dental Practice (2021): 10.5005/jp-journals-10024-3202
\end{abstract}

\section{INTRODUCTION}

Orthodontic treatment duration can be reduced by accelerating the tooth movement since long treatment time is associated with iatrogenic side effects like periodontal issues, demineralization, and root resorption. The mechanical stimulation caused by the appliances used in orthodontic treatment causes remodeling of the bone, adaptation of the periodontal tissues, and consequently, tooth movement takes place. ${ }^{1}$

Many attempts were made to accelerate the tooth movement such as physical trauma by surgical methods (piezopuncture, alveolar corticotomy, micro-osteoperforation, etc.) and by the use of drugs (corticosteroids, vitamin D3, and prostaglandins). ${ }^{2}$ The techniques used previously had disadvantages such as localized pain, decalcification, resorption of roots, and other side effects induced by drugs. ${ }^{3}$ Considering the harmful effects of the previously attempted techniques, a noninvasive method to accelerate the tooth movement was needed. Mechanical vibration is one such method that caused an increase in the rate of orthodontic tooth movement. Literature search revealed that very few studies have been done on mechanical vibration as a means to accelerate tooth movement, and the few which were done were on animals. ${ }^{4-9}$

Low-magnitude and higher frequency mechanical vibration accelerated orthodontic tooth movement without any damage to the periodontal tissues in humans. ${ }^{10}$

It is very important to understand the response of oral biological structures to the applied mechanical loads such as \begin{tabular}{l}
\hline \hline Department of Orthodontics, Sri Rajiv Gandhi College of Dental \\
Sciences and Hospital, Bengaluru, Karnataka, India \\
${ }^{2,3}$ Department of Orthodontics, MS Ramaiah University of Applied \\
Sciences, Bengaluru, Karnataka, India \\
Corresponding Author: Anadha N Gujar, Department of Orthodontics, \\
Sri Rajiv Gandhi College of Dental Sciences and Hospital, Bengaluru, \\
Karnataka, India, Phone: +91 9886360636, e-mail: anadha@gmail.com \\
How to cite this article: Gujar AN, Shivamurthy PG, Sabrish S. Effect of \\
$125-150 \mathrm{~Hz}$ Vibrational Frequency Electric Toothbrush on Teeth and \\
Supporting Structures: A Finite Element Method Study. J Contemp \\
Dent Pract 2021;22(10):1150-1159. \\
Source of support: Nil \\
Conflict of interest: None \\
\hline \hline
\end{tabular}

vibrations in complex stomatognathic systems which can be done more efficiently using computational techniques before using it to accelerate tooth movement in conjunction with orthodontics. ${ }^{11}$ Finite element analysis (FEA) has been widely used in many fields, and it helps in providing concrete information on various aspects. Very few in vitro studies have been done in this regard, and the outcome has been less than satisfactory..$^{11-13}$

The trend of orthodontics practice has evolved from opinionbased practice to evidence-based practice. It has become necessary to plan treatment modalities based on scientific rationale evidence of tissue response to them. ${ }^{12,14,15}$ The advances in modern

() The Author(s). 2021 Open Access This article is distributed under the terms of the Creative Commons Attribution 4.0 International License (https://creativecommons. org/licenses/by-nc/4.0/), which permits unrestricted use, distribution, and non-commercial reproduction in any medium, provided you give appropriate credit to the original author(s) and the source, provide a link to the Creative Commons license, and indicate if changes were made. The Creative Commons Public Domain Dedication waiver (http://creativecommons.org/publicdomain/zero/1.0/) applies to the data made available in this article, unless otherwise stated. 
technology aid the dental profession in carrying out risky and complex procedures in a very reliable and safe manner. ${ }^{16}$ Medical phenomena can be investigated or simulated accurately using this technology, and it is also minimally invasive to the patient. ${ }^{17}$ FEA is a useful mathematical instrument to determine the amount of stress, strain, and displacement in the dentoalveolar complex after using different loading conditions of force. ${ }^{18}$ In orthodontics, FEM has been used in various situations, such as to study the alveolar bone loss, root resorption, changes in the center of rotation, and stress/strain distribution during the tooth movement. ${ }^{19-25}$

Limited information is given in the literature regarding the safe ranges within which vibrations could be applied to the teeth through an electric toothbrush. Hence, with the help of FEA, we have tried to determine the safe span of vibrational frequency for designing a time-controlled multifunctional electric toothbrush.

\section{Materials and Methods}

In this study, the computed tomography (CT) scan of the entire skull of a 22-year-old nonsyndromic, periodontally healthy male patient was used. The CT scan image was obtained using an X-force/SH spiral CT scan machine. Medical modeling software (Materialise's Interactive Medical Image Control System-MIMICS 8.11) was used for the visualization and segmentation of CT images.

The CT image was procured and processed, and the threedimensional (3D) geometric data were constructed using reverse engineering by importing the obtained Digital Imaging and Communications in Medicine (DICOM) data into Rapidform software. An individual geometry consisting of only the surface data of the entire skull including the maxilla, mandible, and its dentition was created. Geometric models of the maxilla and mandible including all the teeth were then imported into the meshing software "HyperMesh 13.0." The individual parts like soft bone, hard bone, teeth, and periodontal ligament (PDL) were discretized (meshing was carried out) and assembled in the HyperMesh software. This meshed model consisting of nodes and element data was the final finite element model (Fig. 1).

The 3D FEA was conducted using a Workstation Intel Core 2 Duo computer $(2.1 \mathrm{GHz})$. The 3D tetrahedral elements were used to create the FE-model. In this study, 378,719 tetrahedral elements and 87,313 nodes were used. The material properties, loads, and boundary conditions were assigned to the FE-model (Fig. 2). The finite element model details (material properties) of the full skull with mandible, maxilla, all teeth, PDL, bones, and sutures are shown in Table 1. The boundary conditions were defined, and the model was fixed to have a zero movement at each degree of freedom.

In a study done by Takano-Yamamoto et al., the acceleration of tooth movement due to supplementary high-frequency vibration was evaluated, and it was found that $150 \mathrm{~Hz}$ produced a static force of $15 \mathrm{~g} \cdot{ }^{26}$ Hence, in this study, we have assumed that the toothbrush vibrating at $150 \mathrm{~Hz}$ frequency would produce a force of $15 \mathrm{~g}$.

The following four situations were considered (Fig. 2):

- Situation 1: Force of $15 \mathrm{~g}$ was applied to maxillary anterior teeth from labial side

- Situation 2: Force of $15 \mathrm{~g}$ was applied to maxillary anterior teeth from palatal side

- Situation 3: Force of $15 \mathrm{~g}$ was applied to mandibular anterior teeth from labial side

- Situation 4: Force of $15 \mathrm{~g}$ was applied to mandibular anterior teeth from lingual side

Linear static analysis was carried out to calculate the primary displacement (sagittal, vertical, and transversal) and the minimum and maximum principal stress levels generated by the force on the maxillary and mandibular dentition, on the maxilla and mandible, and on the whole skull. Although the load was applied to the maxillary and mandibular dentition, we intended to study its effects on not just the dentition, but also on the maxilla, mandible, and the entire skull. The forces applied to the dentition get transmitted to all the three dimensions. They propagate through the jaws and reach the bones of the skull. Hence, the entire skull model was taken into consideration.

\section{Results}

While studying the effects of the force applied to the skull, we observed a minimal displacement of $0.000 \mathrm{~mm}$ and a maximum displacement of $0.004 \mathrm{~mm}$ at the base of the skull in both the situations 1 and 2 (Fig. 3). In situation 1, the maxilla showed a minimal displacement of $0.001 \mathrm{~mm}$ in the pterygoid region (Fig. 4) and maximum displacement of $0.003 \mathrm{~mm}$ (Figs 4A and C). In situation 2, a maximum displacement of $0.004 \mathrm{~mm}$ was seen on the maxillary central and lateral incisor (Figs 4B and D). In both situations 3 and 4, a minimal displacement of $0.000 \mathrm{~mm}$ and a maximum displacement of $0.003 \mathrm{~mm}$ were observed in the condyles (Fig. 5).

In situations 1 and 2, a minimal stress of $0.000 \mathrm{MPa}$ was seen on the entire skull except at the base of the skull $(0.003$
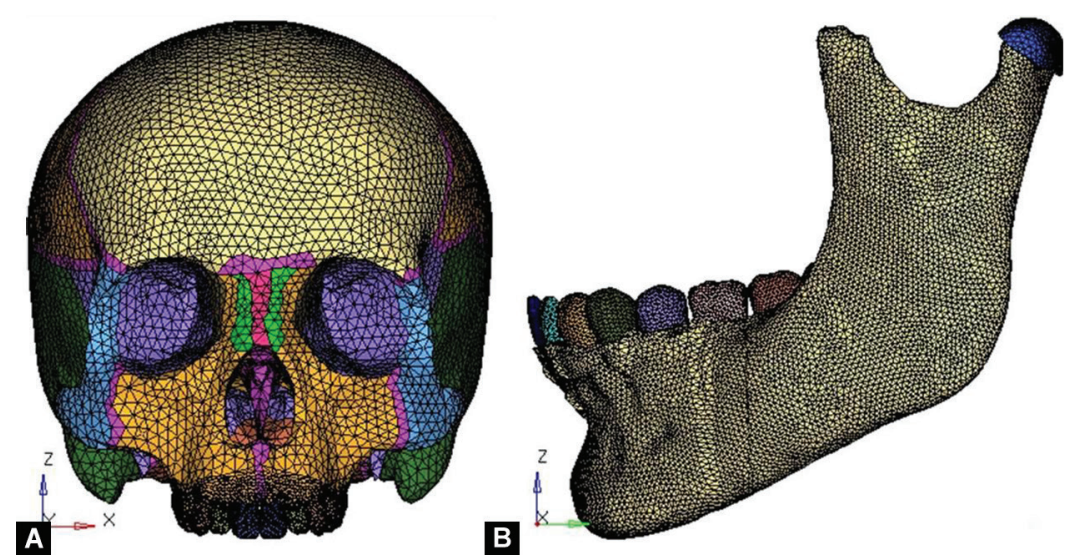

Figs 1 A to C: Hypermeshed model of skull with maxilla, mandible, and their dentitions

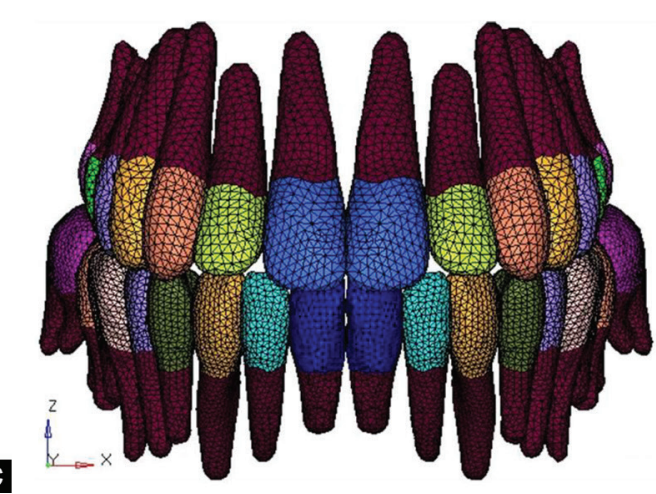




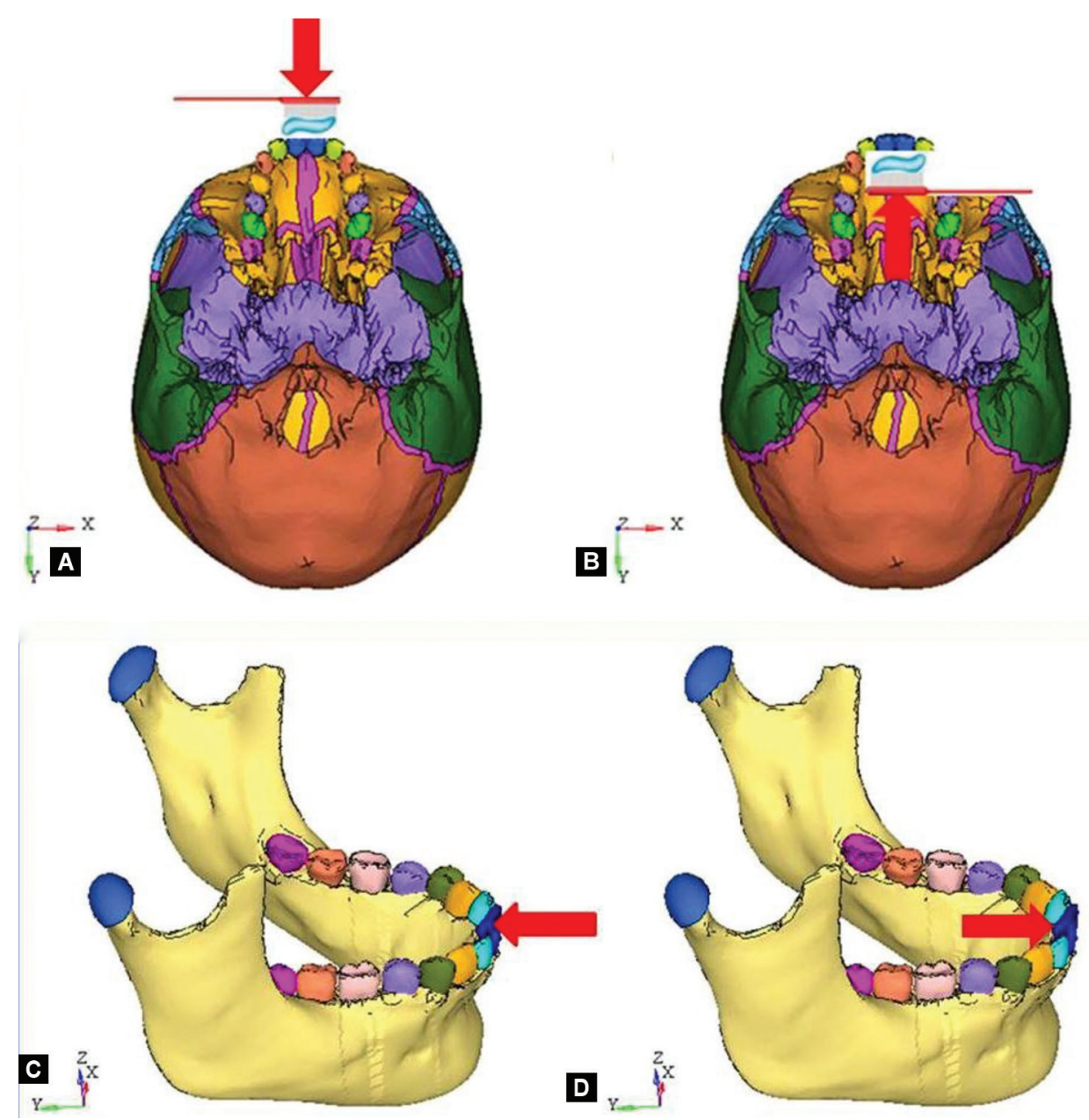

Figs 2A to D: (A) Force of $15 \mathrm{~g}$ applied to maxillary anterior teeth from labial side (situation 1); (B) Force of $15 \mathrm{~g}$ applied to maxillary anterior teeth from palatal side (situation 2); (C) Force of $15 \mathrm{~g}$ applied to mandibular anterior teeth from labial side (situation 3); (D) Force of $15 \mathrm{~g}$ applied to mandibular anterior teeth from lingual side (situation 4)

Table 1: Material properties used for FEA study

\begin{tabular}{lcc}
\hline Part & Elastic modulus $(\mathrm{MPa})$ & Poisson's ratio \\
\hline Cortical bone & 13,700 & 0.3 \\
Cancellous bone & 1,370 & 0.3 \\
Suture & 10 & 0.49 \\
PDL & 0.069 & 0.49 \\
Tooth & 20,700 & 0.3 \\
\hline
\end{tabular}

and $0.004 \mathrm{MPa}$ for labial and palatal applications, respectively) (Fig. 6). In situations 1 and 2, when the effects on the maxilla and its dentition were studied, a maximum stress of $0.017 \mathrm{MPa}$ was seen in both the situations 1 and 2 at the palatal area between the maxillary lateral incisor and canine of both the sides and a minimal stress of $0.000 \mathrm{MPa}$ was seen in both the situations in the rest of the maxilla (Fig. 7).

In situation 3 (Fig. 8), a minimal displacement of $0.000 \mathrm{~mm}$ was seen in the base of the skull and a maximum displacement of $0.004 \mathrm{~mm}$ was seen at the vertex of the skull. Also, minimal displacements were seen at the condyles, and maximum displacement of $0.087 \mathrm{~mm}$ for labial force and $0.086 \mathrm{~mm}$ for lingual force were seen at the mental protuberance (Figs $9 \mathrm{~A}$ and B). In situation 3, the displacement ranged from a minimum of $0.024 \mathrm{~mm}$ to a maximum of $0.078 \mathrm{~mm}$ distal to the molars, and in situation 4 , the displacement ranged from a minimum of $0.077 \mathrm{~mm}$ to a maximum of $0.025 \mathrm{~mm}$ in the mandibular incisors (Figs $9 C$ and $D$ ).

In situation 3, the stresses generated on the mandible at the ramus were a minimum of $0.00 \mathrm{MPa}$ and a maximum of $0.085 \mathrm{MPa}$. When we studied the effects on the mandibular dentition, a minimum stress of $0.00 \mathrm{MPa}$ was seen on the molars and incisal surfaces of mandibular incisors (Fig. 10).

Table 2 shows the displacements and stresses produced after the load application on the maxillary anteriors in situations 1 and 2 . The displacements and stresses produced after the load application on the mandibular anteriors in situations 3 and 4 are shown in Table 3.

\section{Discussion}

Bone is a dynamic tissue that is subjected daily to a variety of mechanical loading. It has the capacity to structurally adapt by changing its mass, morphology, architecture, and density, in response to mechanical loading through the process of bone remodeling. Since the bone cells are sensitive to their environment, they can detect chemical and mechanical signals. ${ }^{26}$ 

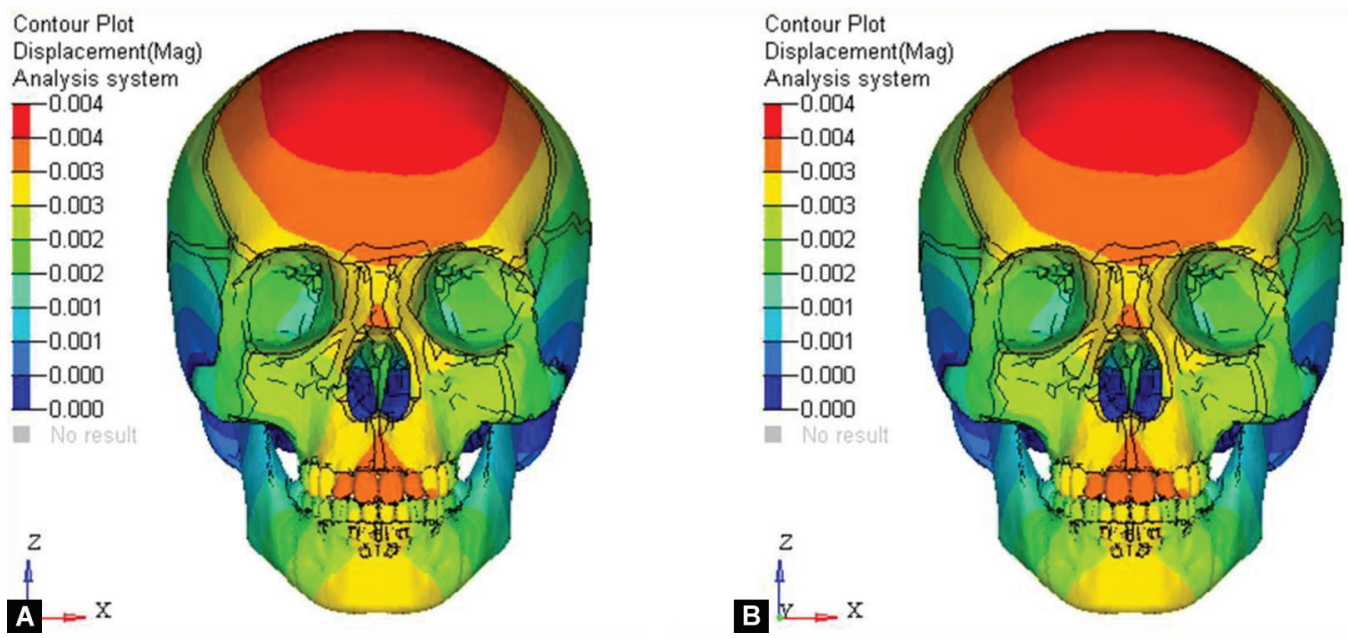

Figs $3 \mathrm{~A}$ and B: (A) Displacement contours on whole skull (situation 1); (B) Displacement contours on whole skull (situation 2)

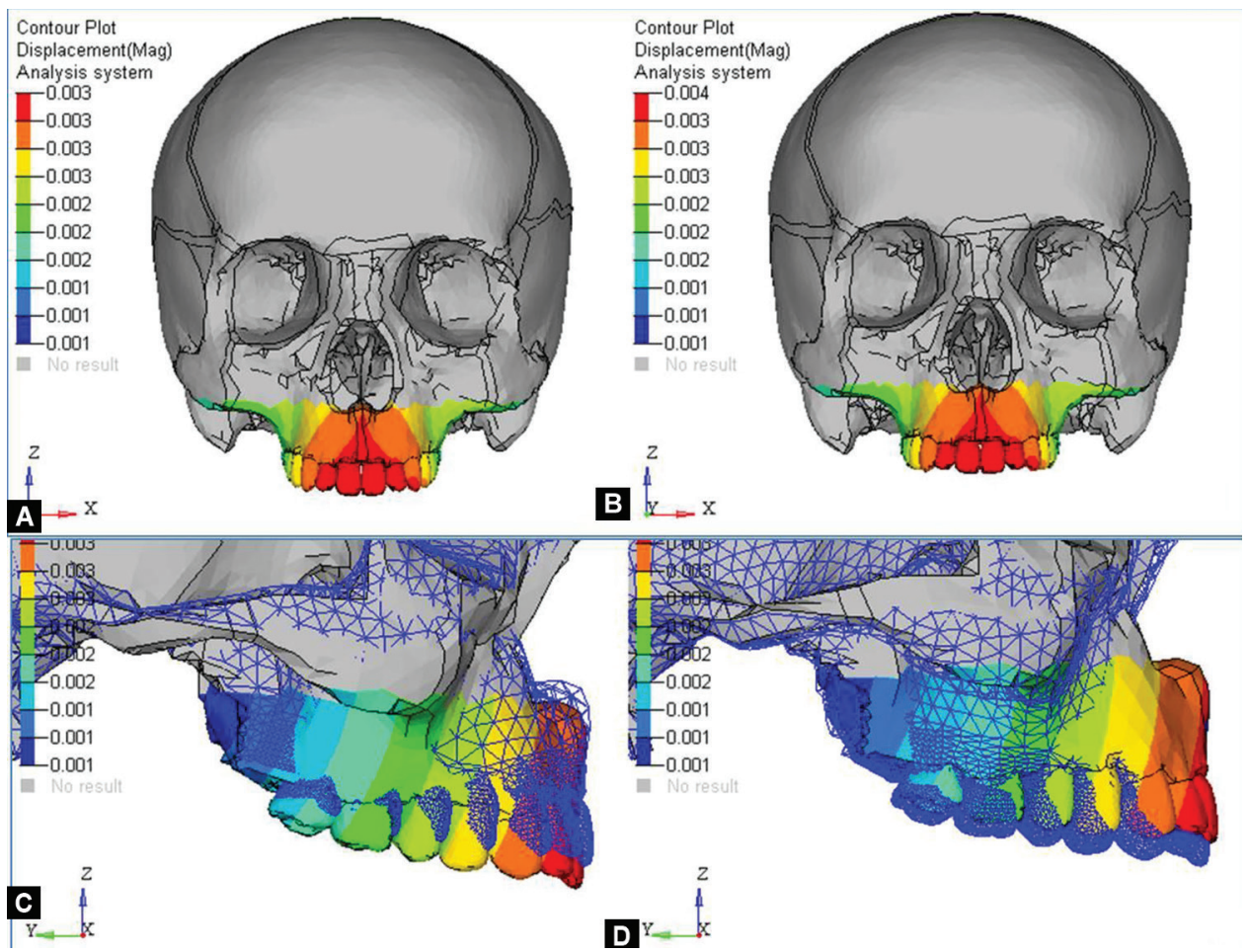

Figs 4A to D: (A) Displacement contours on maxilla (situation 1); (B) Displacement contours on maxilla (situation 2); (C) Displacement contours on maxillary dentition (situation 1); (D) Displacement contours on maxillary dentition (situation 2)

Orthodontic appliances apply forces on the tooth crown, and this is transferred to the surrounding periodontal tissues. The magnitude of force applied is crucial since high forces may lead to root resorption and such damage is irreversible. ${ }^{27,28}$

A large number of manual and electronic toothbrushes are available in the market today. There has not been any detailed evaluation on the effect of the forces applied by such devices. According to a study done by Burgett and Ash, the hard manual toothbrush created an in vivo mean maximum pressure of $19.53 \pm 6.48 \mathrm{~g} / \mathrm{mm}^{2}$, the soft manual toothbrush applied $11.32 \pm 5.32 \mathrm{~g} / \mathrm{mm}^{2}$, whereas the powered toothbrush applied $11.29 \pm 5.02 \mathrm{~g} / \mathrm{mm}^{2}$ pressure. $^{29}$ There have been a few studies conducted on the effects of forces generated by toothbrushing. They have reported that the mean maximum brushing force varies a great deal, but they have not assessed if the forces produced any detrimental effects. ${ }^{30-38}$

Several engineering fields use numerical simulations (FEA) to research certain problems. FEA is a well-known method used to solve the problems of complex geometry and loading conditions that are not solved analytically. In FEA, the structure is divided into various small elements that are connected by mesh intersections or nodes, and this process is called meshing. The forces are applied to simulate applied loads and boundary conditions are defined to constrain the structure. ${ }^{39}$ Studies have shown that the finite element 

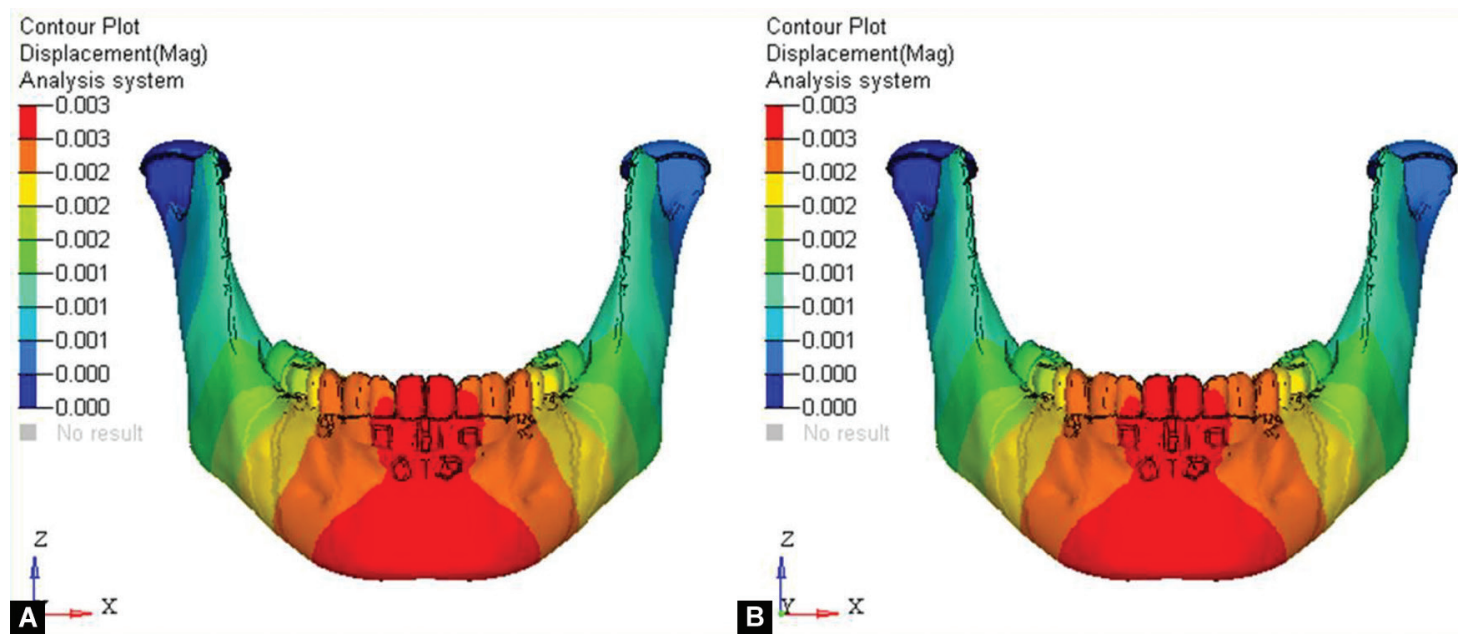

Figs 5A and B: (A) Displacement contours on mandible (situation 1); (B) Displacement contours on mandible (situation 2)
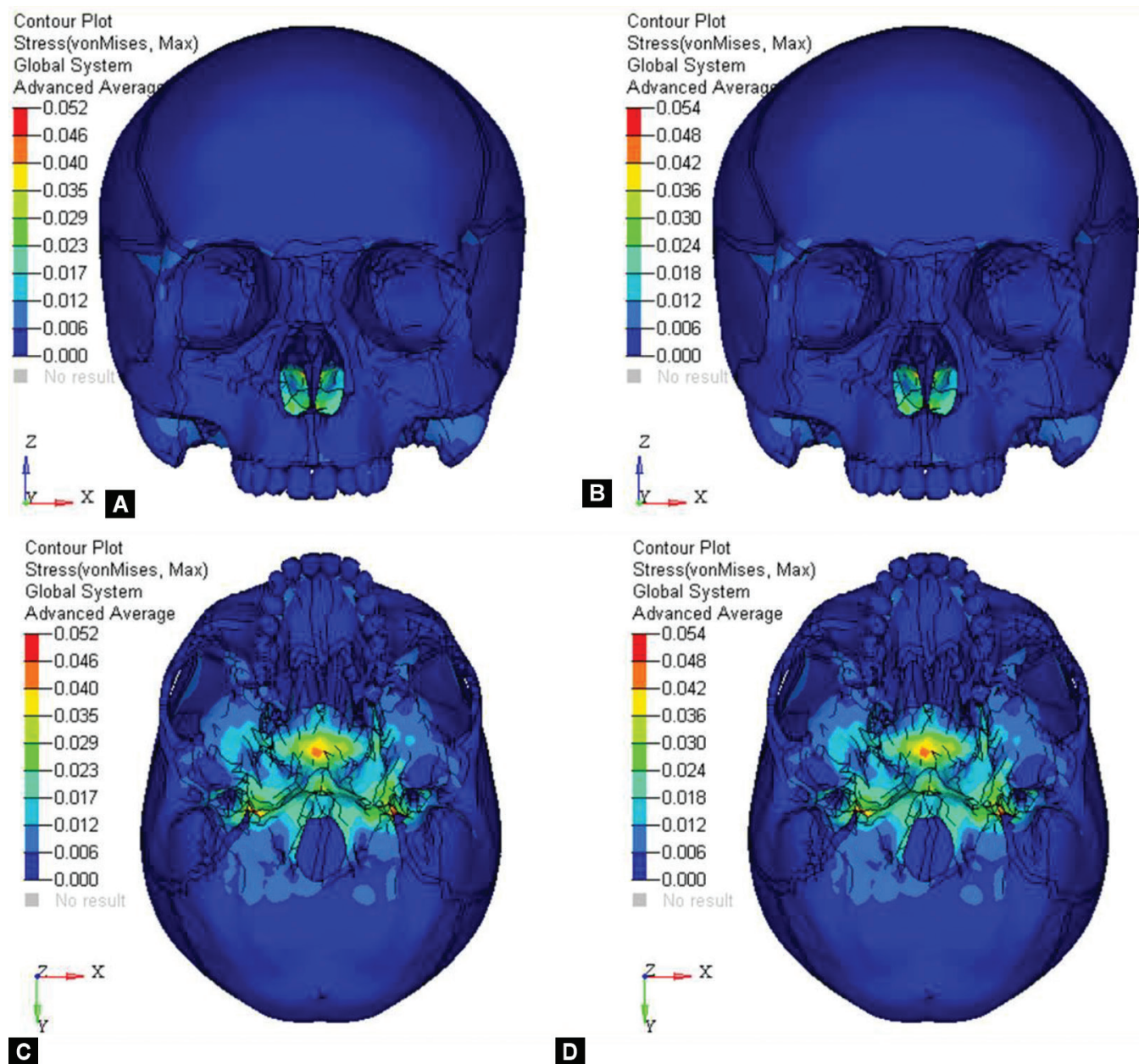

D

Figs 6A to D: (A and C) Stress contours on whole skull (situation 1); (B and D) Stress contours on whole skull (situation 2)

method (FEM) can be applied to the study of the stress and strain levels induced in internal structures. ${ }^{40,41}$ FEM offers a useful method for accurate modeling of the tooth-periodontium system with its complicated 3D geometry. ${ }^{40}$
A study was conducted by Wiegand et al. to determine the forces applied during toothbrushing with manual and sonic toothbrushes. Their results showed that the average force applied by the manual toothbrush $(1.6 \pm 0.3 \mathrm{~N})$ was higher than that applied by the sonic 


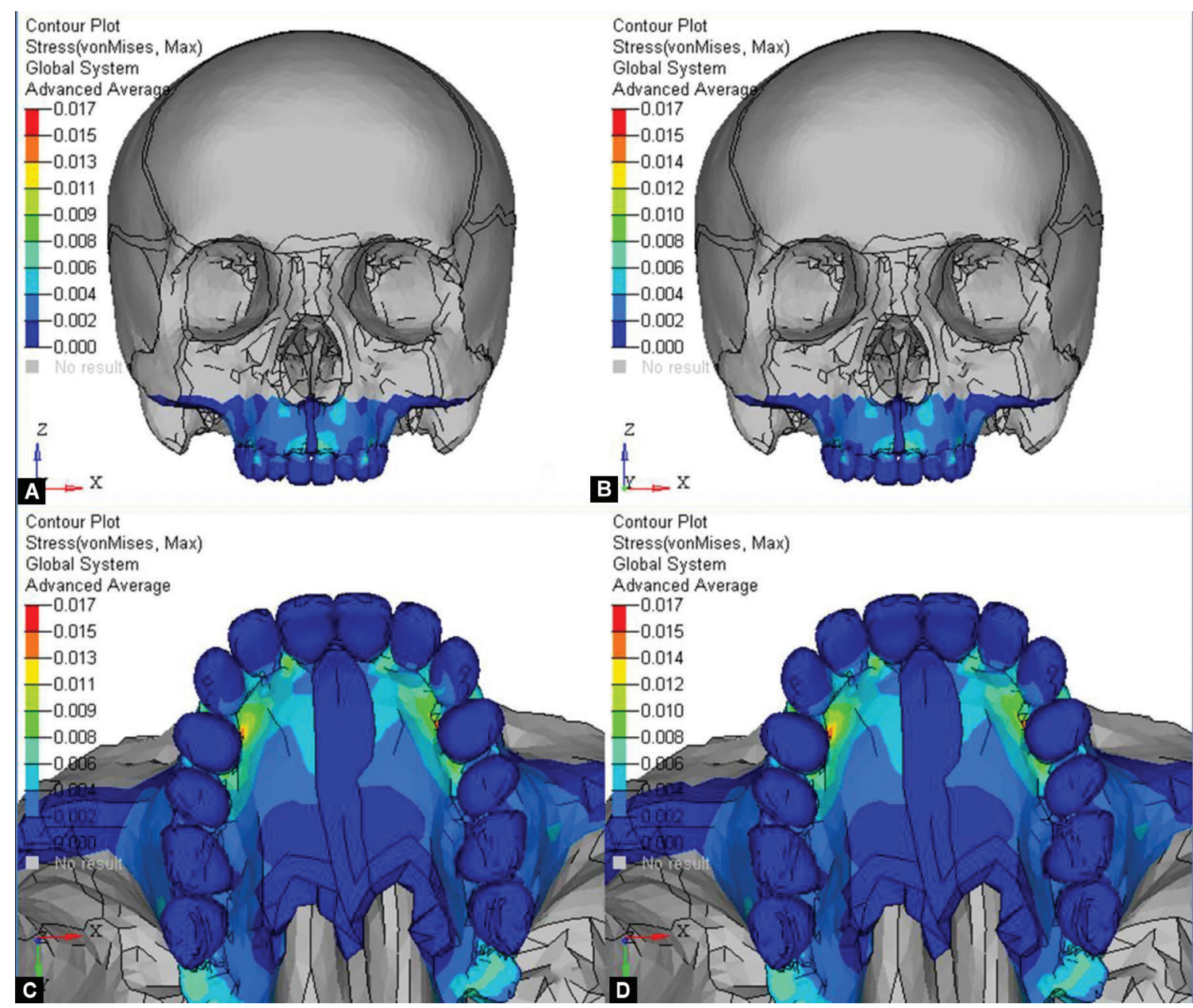

Figs 7A to D: (A) Stress contours on maxilla and its dentition (situation 1); (B) Stress contours on maxilla and its dentition (situation 2); (C) Stress contours on maxilla and its dentition (situation 1); (D) Stress contours on maxilla and its dentition (situation 2)
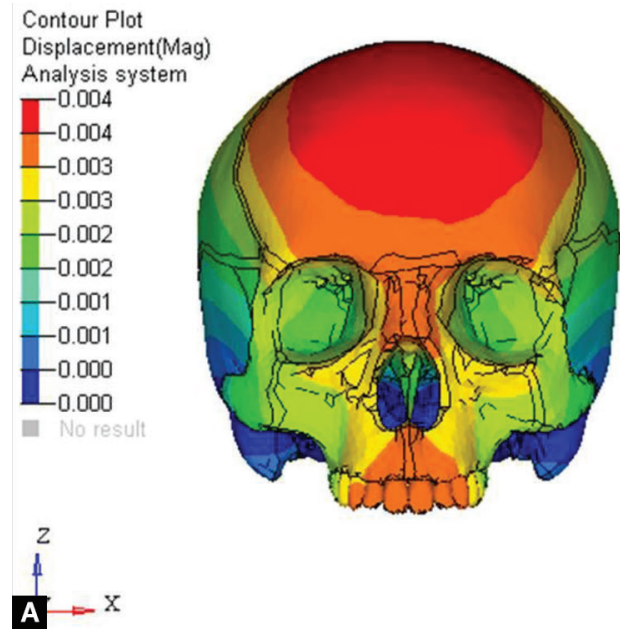

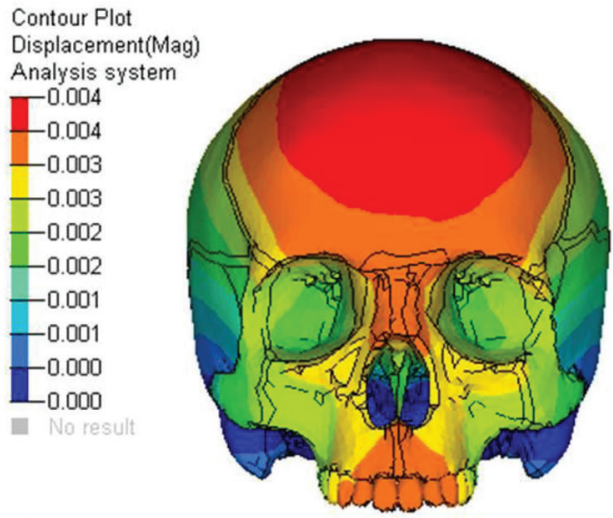

B $t^{2}=x$

Figs 8A and B: (A) Displacement contours on whole skull (situation 3); (B) Displacement contours on whole skull (situation 4)

toothbrushes $(0.9 \pm 0.2 \mathrm{~N})$, but the difference was not significant. The brushing force was measured by an experimental model designed by the authors. ${ }^{42}$

According to a study done by Muneer et al., forces of 5, 15, 24, and $29 \mathrm{~kg}$ applied to the middle third of the crown on the palatal surface of incisor tooth at an angle of $50^{\circ}$ in palato-labial direction represented the forces of normal occlusion. Force values of $5 \mathrm{~kg}$ $(50 \mathrm{~N})$ represented hypofunction as it was very minimal compared to the average force on the tooth while $24 \mathrm{~kg}(240 \mathrm{~N})$ and $29 \mathrm{~kg}(290 \mathrm{~N})$ represented hyperfunction. ${ }^{43}$ 


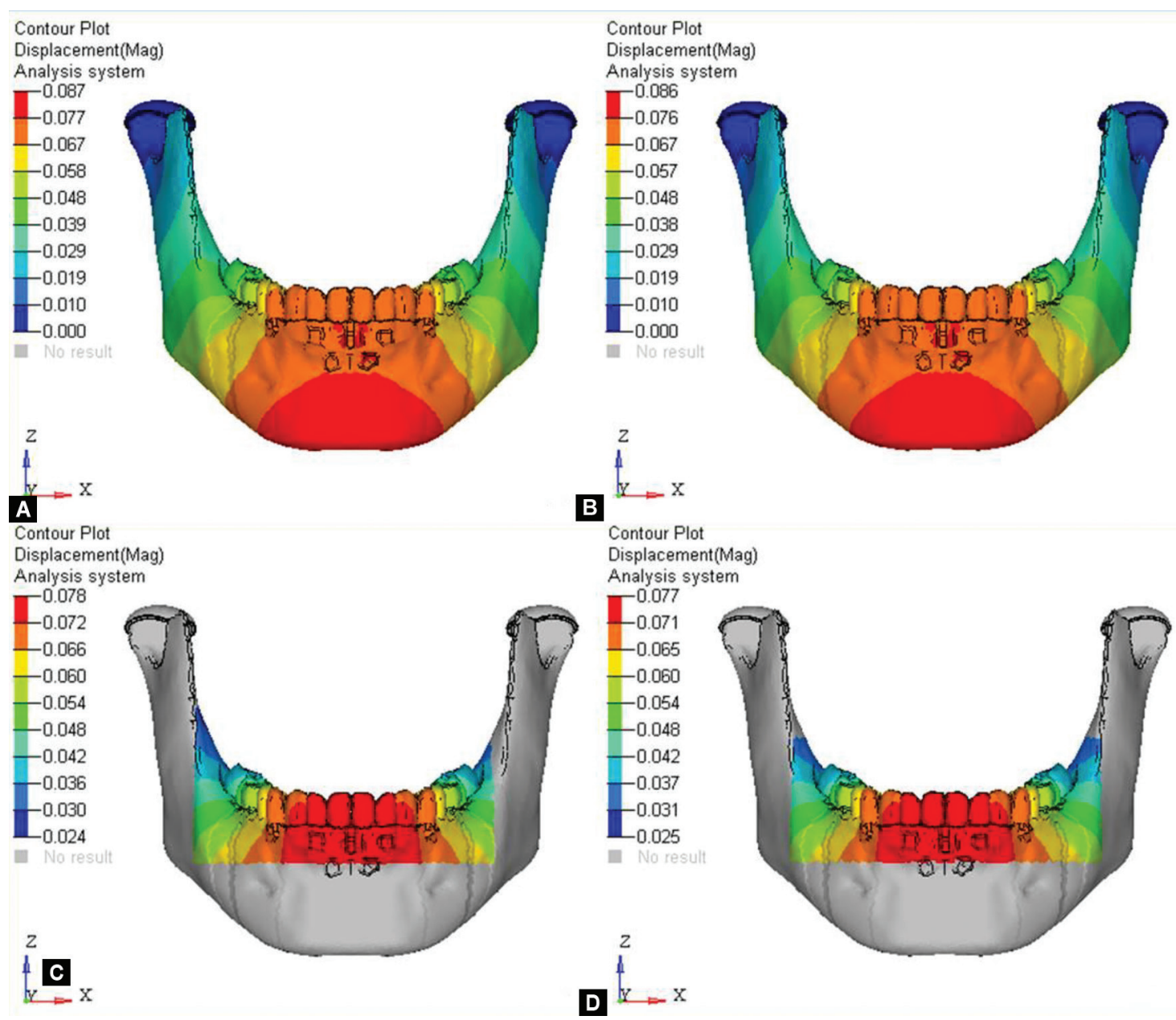

Figs 9A to D: (A) Displacement contours on mandible (situation 3); (B) Displacement contours on mandible (situation 4); (C) Displacement contours on mandibular dentition (situation 3); (D) Displacement contours on mandibular dentition (situation 4)

At a load of $15 \mathrm{~kg}(150 \mathrm{~N})$ (normofunction), the minimum stress was $-1.18 \mathrm{MPa}$ and the maximum stress was $-10.93 \mathrm{MPa}$. Similarly, the minimum and maximum stresses of -0.39 and $-3.64 \mathrm{MPa}$ were seen with $5 \mathrm{~kg}$ load, -1.88 and $-17.49 \mathrm{MPa}$ with $24 \mathrm{~kg}$ load, and -2.28 and $-21.13 \mathrm{MPa}$ with $29 \mathrm{~kg}$ load. In this study, at all values of loading, the maximum tooth displacement was noted at the incisal edge and minimum tooth displacement was at the cervical third of the root. ${ }^{43}$

Reddy and Vandana studied the von Mises stresses using a 3D FEM model of the maxillary central incisor tooth, its PDL, and alveolar bone due to a higher load of $24 \mathrm{~kg}$ applied to its palatal surface in palato-labial direction at the level of the middle third of crown at an angle of $50^{\circ}$ to the long axis of the tooth. The maximum stress measured was $21.676 \mathrm{MPa} .^{44}$

The teeth and the jaws are subjected to the opposing forces from the buccal tissues and the tongue. Valentim et al. ${ }^{45}$ evaluated the physiological forces applied by the tongue and lip on maxillary central incisor tooth. At rest, the force exerted by the lip on the maxillary central incisor was $0.02 \pm 0.02 \mathrm{~N}$ and this was higher than the force exerted by the tongue $(0.00 \pm 0.00 \mathrm{~N})$. During swallowing, the forces exerted by the lip on the tooth were $0.03 \pm 0.38 \mathrm{~N}$ and the forces exerted by the tongue were $0.15 \pm 0.14 \mathrm{~N}$, and there was no significant difference between them. It can be concluded that these forces are very too small to cause any displacement or stress on the dentition or the jaws.
Therefore, in our study, these physiological forces would not affect our observations. ${ }^{45}$

In a study by Takano-Yamamoto et al. ${ }^{26}$ where they evaluated in rats that the acceleration of tooth movement induced by supplementary high-frequency vibration, it was observed that at $150 \mathrm{~Hz}$ vibration, a static force of $15 \mathrm{~g}$ was produced. Hence, in our study, we have assumed that a toothbrush producing up to $150 \mathrm{~Hz}$ of vibration frequency would generate a force magnitude of around $15 \mathrm{~g}$.

In this study, we have evaluated the effect of the vibrations from the brushing forces applied to maxillary and mandibular anteriors by analyzing the stresses and displacements on the skull using 3D FEM.

The forces applied from the labial and palatal sides produced a minimal displacement at the base of the skull $(0.000 \mathrm{~mm})$ and a maximum displacement at the vertex of the skull $(0.004 \mathrm{~mm})$ (Fig. 3). The force's effect on the maxilla was a minimal displacement of $0.001 \mathrm{~mm}$ in the pterygoid region (Fig. 4) and a maximum displacement of $0.003 \mathrm{~mm}$ on the maxillary central and lateral incisors when labial brushing forces were applied from labial aspect (Figs 4A and C). The maximum displacement of $0.004 \mathrm{~mm}$ was seen on the maxillary central and lateral incisors when brushing forces were applied from palatal direction (Figs $4 B$ and D). The effects of brushing forces in both the situations involving the mandible 


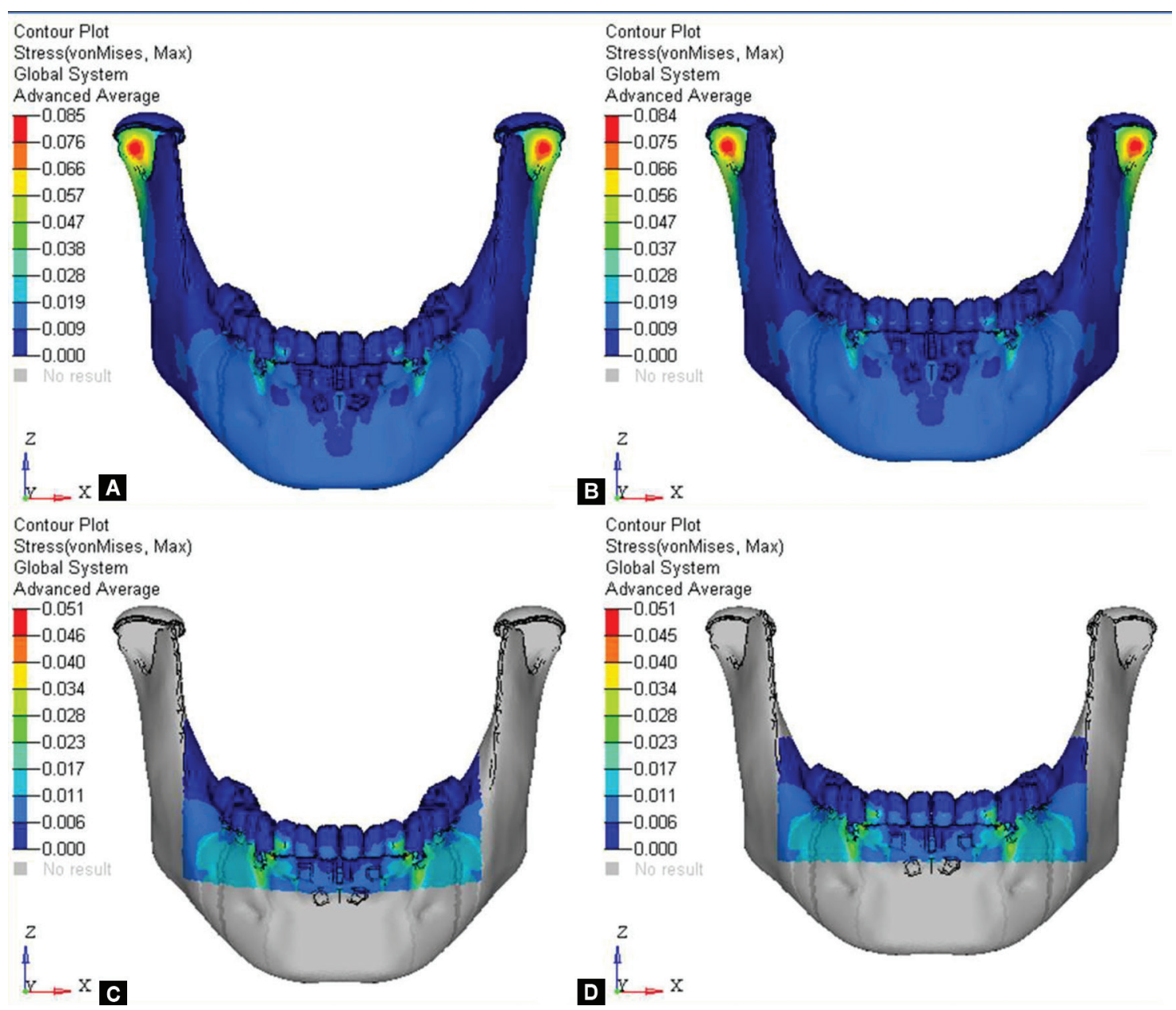

Figs 10A to D: (A) Stress contours on mandible (situation 3); (B) Stress contours on mandible (situation 4); (C) Stress contours on mandibular dentition (situation 3); (D) Stress contours on mandibular dentition (situation 4)

Table 2: Load on maxillary anterior region (situations 1 and 2)

\begin{tabular}{lcc}
\hline Loading direction & Deflection $(\mathrm{mm})$ & Stress $(\mathrm{MPa})$ \\
\hline Buccal side & 0.003 & 0.004 \\
Lingual side & 0.017 & 0.017 \\
\hline
\end{tabular}

Table 3: Load on mandibular anterior region (situations 3 and 4)

\begin{tabular}{lcc}
\hline Loading direction & Deflection $(\mathrm{mm})$ & Stress $(\mathrm{MPa})$ \\
\hline Buccal side & 0.078 & 0.051 \\
Lingual side & 0.077 & 0.051 \\
\hline
\end{tabular}

showed that the minimal displacement of $0.000 \mathrm{~mm}$ was seen in the condyles and the maximum displacement of $0.003 \mathrm{~mm}$ was seen on the mandibular central and lateral incisors (Fig. 5).

The stresses produced on the skull were also evaluated. We observed very minimal stress $(0.000 \mathrm{MPa})$ on the entire skull except at the base of the skull (0.003 and $0.004 \mathrm{MPa}$ for labial and palatal application, respectively) (Fig. 6). The applied forces also produced stresses on the maxilla and its dentition. A maximum stress of $0.017 \mathrm{MPa}$ was seen at the palatal area between the maxillary lateral incisor and canine of both the sides and in the rest of the entire maxilla minimal stress of $0.000 \mathrm{MPa}$ was seen in both the situations (Fig. 7). When we studied the effects of brushing force on the anteriors of mandible, a minimal displacement of $0.000 \mathrm{~mm}$ was seen in the base of the skull and a maximum displacement of $0.004 \mathrm{~mm}$ was seen at the vertex of the skull. Also, minimal displacements were seen at the condyles and maximum displacements of $0.087 \mathrm{~mm}$ for labial force and $0.086 \mathrm{~mm}$ for lingual force were seen at the mental protuberance (Figs $9 \mathrm{~A}$ and B). Also, in situation 3 in the mandibular teeth, the displacement distal to molars was found to be a minimum of $0.024 \mathrm{~mm}$ and a maximum of $0.078 \mathrm{~mm}$. In situation 4, it ranged from 0.025 to $0.077 \mathrm{~mm}$ at the mandibular incisors (Figs $9 \mathrm{C}$ and $\mathrm{D}$ ).

The stresses generated on the mandible in both situations were a minimum of $0.00 \mathrm{MPa}$ at the ramus and a maximum of $0.085 \mathrm{MPa}$ for labial force and $0.084 \mathrm{MPa}$ for lingual force at the condylar neck bilaterally. When we studied the effects of brushing forces only on the mandibular dentition, a minimum stress of $0.00 \mathrm{MPa}$ was seen on the molars and incisal surfaces of mandibular incisors (Fig. 10).

The displacements and stresses produced after the load application on the maxillary anteriors in situations 1 and 2 as shown in Table 2 were very minimal. The displacements and stresses produced after the load application on the mandibular anteriors in both the situations 3 and 4 as shown in Table 3 were also very minimal. Comparing the loads during the normofunction as stated 
in the previous studies, ${ }^{43-46}$ the effects of the loads obtained in our study were extremely minimal or negligible.

\section{Conclusion}

Force of $15 \mathrm{~g}$ applied to maxillary anterior teeth from labial side caused a mean deflection of $0.003 \mathrm{~mm}$ and stress of $0.004 \mathrm{MPa}$ on the teeth and supporting structures. Force of $15 \mathrm{~g}$ applied to maxillary anterior teeth from palatal side caused a mean deflection of $0.017 \mathrm{~mm}$ and stress of $0.017 \mathrm{MPa}$ on the teeth and supporting structures. Force of $15 \mathrm{~g}$ applied to mandibular anterior teeth from labial side caused a mean deflection of $0.078 \mathrm{~mm}$ and stress of $0.051 \mathrm{MPa}$ on the teeth and supporting structures. Force of $15 \mathrm{~g}$ applied to mandibular anterior teeth from lingual side caused a mean deflection of $0.077 \mathrm{~mm}$ and stress of $0.051 \mathrm{MPa}$ on the teeth and supporting structures.

For the applied loads and boundary conditions, we found out that very small or negligible amounts of stresses were observed in maxilla, mandible, and their dentitions. The vibrational frequency of $150 \mathrm{~Hz}$ producing $15 \mathrm{~g}$ of force did not produce any harmful effects on the maxilla, mandible, and their dentitions.

\section{References}

1. Sumit S. Change in the rate of Orthodontic tooth movement and Interleukin-1 beta level in gingival crevicular fluid in response to mechanical vibratory stimulation from electrical toothbrush [Master of science thesis]. University of Prince of Songkla; 2010.

2. Mostafa MM. Developing a corticopuncture system to accelerate the rate of tooth movement [Master of science thesis]. University of California Los Angeles; 2014.

3. Thomas GD. The effect of varying frequencies of mechanical vibration on the rate of orthodontic tooth movement in mice [Master's thesis]. University of Connecticut School of Medicine and Dentistry; 2013.

4. Dubravko P, Ravikumar A, Vishnu R, et al. Cyclic loading (vibration) accelerates tooth movement in orthodontic patients: a double-blind, randomized controlled trial. Semin Orthod 2015;21(3):187-194. DOI: 10.1053/j.sodo.2015.06.005.

5. Kawasaki K, Shimizu N. Effects of low-energy laser irradiation on bone remodeling during experimental tooth movement in rats. Lasers Surg Med 2000;26(3):282-291. DOI: 10.1002/(sici)10969101(2000)26:3<282::aid-Ism6>3.0.co;2-x.

6. Stark TM, Sinclair PM. Effect of pulsed electromagnetic fields on orthodontic tooth movement. Am J Orthod Dentofacial Orthop 1987;91(2):91-94. DOI: 10.1016/0889-5406(87)90465-3.

7. Yamasaki K, Shibata Y, Imai S, et al. Clinical application of prostaglandin E1 (PGE1) upon orthodontic tooth movement. Am J Orthod Dentofacial Orthop 1984;85(6):508-518. DOI: 10.1016/00029416(84)90091-5.

8. Takano-Yamamoto T, Kawakami M, Yamashiro T. Effect of age on the rate of tooth movement in combination with local use of 1,25(OH)2D3 and mechanical force in the rat. J Dent Res 1992;71(8):1487-1492. DOI: 10.1177/00220345920710080501.

9. Brudvik P, Rygh P. Root resorption after local injection of prostaglandin E2 during experimental tooth movement. Eur J Orthod 1991;13(4):255-263. DOI: 10.1093/ejo/13.4.255.

10. Chidchanok L, Sumit S, Suwanna J, et al. Vibratory stimulation increases interleukin-1 beta secretion during orthodontic tooth movement. Angle Orthod 2016;86(1):74-80. DOI: 10.2319/111914830.1.

11. Piccioni MA, Campos EA, Saad JR, et al. Application of the finite element method in dentistry. RSBO 2013;10:369-377.

12. Sarmah A, Mathur AK, Gupta V, et al. Finite element analysis of dental implant as orthodontic anchorage. J Contemp Dent Pract 2011;12(4):259-264. DOI: 10.5005/jp-journals-10024-1044.
13. Singh $J R$, Kambalyal $P$, Jain $M$, et al. Revolution in orthodontics: finite element analysis. J Int Soc Prevent Commun Dent 2016;6(2):110-114. DOI: 10.4103/2231-0762.178743.

14. Ansari TA, Mascarenhas R, Husain A, et al. Evaluation of the power arm in bringing about bodily movement using finite element analysis. Orthodontics (Chic.) 2011;12(4):318-329. PMID: 22299105.

15. Bica C, Brezeanu L, Bica D, et al. Biomechanical reactions due to orthodontic forces. A finite element study. Procedia Tech 2015;19:895-900. DOI: 10.1016/j.protcy.2015.02.128.

16. Hamnaka R, Yamoaka S, Anh TN, et al. Numeric simulation model for long term orthodontic tooth movement with contact boundary conditions using the finite element method. Am J Orthod Dentofacial Orthop 2017;152(5):601-612. DOI: 10.1016/j.ajodo.2017.03.021.

17. Bozkurt AP, Clinsar A. Effects of mechanical vibration force on tooth movement: finite element analysis. Int J Res Granthaalayah 2018;6(1):504-515. DOI: 10.29121/granthaalayah.v6.i1.2018.1671.

18. Bai D, Cheng BH, Lu T. Three dimensional finite element analysis of maxillary canine during the tooth translation movement. Sichuan Da Xue Bao Yi Xue Ban 2004;35(3):358-360. PMID: 15181835.

19. Geramy A. Alveolar bone resorption and the center of resistance modification (3-D analysis by means of the finite element method). Am J Orthod Dentofacial Orthop 2000;117(4):399-405. DOI: 10.1016/ s0889-5406(00)70159-4.

20. Kojima Y, Fukui H. Numerical simulation of canine retraction by sliding mechanics. Am J Orthod Dentofacial Orthop 2005;127(5):542-551. DOI: 10.1016/j.ajodo.2004.12.007.

21. Kojima Y, MizunoT, Fukui H. A numerical simulation of tooth movement produced by molar uprighting spring. Am J Orthod Dentofacial Orthop 2007;132(5):630-638. DOI: 10.1016/j.ajodo.2005.07.035.

22. Yettram AL, Wright KW, Pickard HM. Finite element stress analysis of the crowns of normal and restored teeth. J Dent Res 1976;55(6):10041011. DOI: $10.1177 / 00220345760550060201$.

23. Vasquez $M$, Calao $E$, Becerra F, et al. Initial stress differences between sliding and sectional mechanics with an endosseous implant as anchorage: A 3-dimensional finite element analysis. Angle Orthod 2001;71(4):247-256. DOI: 10.1043/0003-3219(2001)071<0247: ISDBSA>2.0.CO;2.

24. Chan E, Darendeliler MA. Physical properties of root cementum: Part 7. Extent of root resorption under areas of compression and tension. Am J Orthod Dentofacial Orthop 2006;129(4):504-510. DOI: 10.1016/ j.ajodo.2004.12.018.

25. Chan E, Darendeliler MA. Physical properties of root cementum: Part 5. Volumetric analysis of root resorption craters after application of light and heavy orthodontic forces. Am J Orthod Dentofacial Orthop 2005;127(2):186-195. DOI: 10.1016/j.ajodo.2003.11.026.

26. Takano-Yamamoto T, Sasaki K, Fatemeh G, et al. Synergistic acceleration of experimental tooth movement by supplementary high-frequency vibration applied with a static force in rats. Sci Rep 2017;7(1):1-7. DOI: 10.1038/s41598-017-13541-7.

27. Hohmann A, Wolfram U, Geiger M, et al. Periodontal ligament hydrostatic pressure with areas of root resorption after application of a continuous torque moment. Angle Orthod 2007;77(4):653-659. DOI: 10.2319/060806-234.

28. $\operatorname{Kim} \mathrm{T}$, Suh J, Kim N, et al. Optimum conditions for parallel translation of maxillary anterior teeth under retraction force determined with the finite element method. Am J Orthod Dentofacial Orthop 2010;137(5):639-647. DOI: 10.1016/j.ajodo.2008.05.016.

29. Burgett FG, Ash MM. Comparative study of the pressure of brushing with three types of toothbrushes. J Periodontol 1974;45(6):410-413. DOI: 10.1902/jop.1974.45.6.410.

30. Björn H, Lindhe J. On the mechanics of toothbrushing. Odontol Revy 1966;17(1):9-16. PMID: 5218905.

31. Fraleigh CM, Mc Elhaney JH, Heiser RA. Toothbrushing force study. J Dent Res 1967;46(1):209-214. DOI: 10.1177/002203456704600 11201.

32. Gorman WJ. Prevalence and etiology of gingival recession. J Periodontol 1967;38(4):316-322. DOI: 10.1902/jop.1967.38.4.316. 
33. Kimmelman BB, Tarin B, Paschis AE. Research in tooth brush design. Pennsylvania Dent J 1958;25:24-28.

34. Kitchin PC. The prevalence of tooth root exposure, and the relation of the extent of such exposure to the degree of abrasion in different age classes. J Dent Res 1941;20:565-574. DOI: 10.1177/ 00220345410200060801.

35. Manly RS, Foster DH. Importance of factorial designs in testing abrasion by dentifrices. J Dent Res 1967;46(2):442-445. DOI: 10.1177/00220345670460022201.

36. Mannerberg F. Appearance of tooth surface as observed in shadow replicas in various age groups, in long-term studies, after toothbrushing, in cases of erosion, and after exposure to citrus fruit juice. Odont Revy 1960;2:70-79.

37. O'Leary TJ, Drake RB, Gividen GJ, et al. The incidence of recession in young males. Relationship to gingival health and plaque. Periodontics 1968;6:109-119.

38. PhaneufEA, Harrington JH, Dale PP, et al. Automatic toothbrush: a new reciprocating action. J Am Dent Assoc 1962;65:12-25. DOI: 10.14219/ jada.archive.1962.0187.

39. Jian-lei WU, Yun-feng LIU, Wei P, et al. A biomechanical case study on the optimal orthodontic force on the maxillary canine tooth based on finite element analysis. J Zhejiang Univ-Sci B 2018;19(7):535-546. DOI: 10.1631/jzus.B1700195.
40. Miyashita ER, Mattos BC, Noritomi PN, et al. Finite element analysis of maxillary bone stress caused by Aramany Class IV obturator prostheses. J Prosthet Dent 2012;107(5);336-342. DOI: 10.1016/S00223913(12)60086-9.

41. Pytel A, Singer FL. Simple stress. In: Strength of materials. 4th ed. Harpercollins College Div; 1987.

42. Wiegand A, Burkhard JP, Eggmann F, et al. Brushing force of manual and sonic toothbrushes affects dental hard tissue abrasion. Arch Oral Biol 2007;52(11):1043-1047. DOI: 10.1007/s00784-0120788-z.

43. Muneer S, Vandana KL. Effect of different occlusal loads on periodontium: a three-dimensional finite element analysis. CODS J Dent 2016;8(2):78-80. DOI: 10.5005/jp-journals-100630018.

44. Reddy MK, Vandana KL. Three dimensional finite element analysis of stress in the periodontium. J Int Acad Periodontol 2005;7(4):102-107. PMID: 16245640.

45. Valentim AF, Furlan RMMM, Perilo TVC, et al. Evaluation of the force applied by the tongue and lip on the maxillary central incisor tooth. CoDAS 2014;26(3):235-240. DOI: 10.1590/2317-1782/2014201 30077.

46. Kimmelman BB, Tarin B, Paschis AE, et al. Research in tooth brush design. Pennsylvania Dent J 1958;25:4-24. 